\title{
RADIOCARBON DATING OF THE MANSURI PALEOLITHIC SITE, CHEONGWON, KOREA
}

\author{
K J Kim ${ }^{1,2} \bullet$ A J T Jull ${ }^{3}$ Ju Yong Kim ${ }^{1}$ Yung Jo Lee • Wan Hong $^{1} \bullet$ Jung Hun Park $^{1} \bullet$ \\ Hyung Joo Woo ${ }^{1}$
}

\begin{abstract}
Construction of a new science complex in Osong, Cheongwon-gun, Korea, has allowed the investigation of 14 different Paleolithic localities, excavated during 2005-2007. Here, we investigated localities 1 and 12 of the Mansuri Paleolithic site to obtain chronological information using radiocarbon dating. The soil deposition rates varied from 0.09 to 0.15 $\mathrm{mm} / \mathrm{yr}$ over the period ranging from 33 to $31 \mathrm{kyr}$ BP for locality 1 . Locality 12 samples were more recent, $<10 \mathrm{ka}$, and have similar accumulation rates, averaging $0.11 \mathrm{~mm} / \mathrm{yr}$. The soil ages of locality 12 were found to be younger than $10 \mathrm{kyr}$ BP. Results for both soil and organic materials at this locality gave much younger ages at shallower depths than the ages expected by the Korean Paleolithic cultural history for this region. Therefore, these more recent deposits may not be associated with the cultural layers and are interpreted to have been hydrologically modified following emplacement. ${ }^{14} \mathrm{C}$ dates of the soil and organic materials at locality 12 confirm that there is evidence for multiple human occupations throughout the last 9 kyr BP.
\end{abstract}

\section{INTRODUCTION}

Development of a new science complex in Osong, Cheongwon-gun, has afforded Korean archaeologists the opportunity to investigate 14 different Paleolithic localities during a 2-yr period (20052007). The localities collectively equal a total excavated area of $29,776 \mathrm{~m}^{2}$. Here, we investigate the samples collected at localities 1 and 12 (Figure 1). Locality 1 (38 m asl) shows a $\sim 10$-m-thick soil profile on bedrock, which comprises 13 distinct layers (Figure 2). Optically stimulated luminescence (OSL) dating of 5 of the 13 layers at different elevations is inconsistent with both their radiocarbon-dated ages and stratigraphic positions (Figure 2) (Lee 2007; Lee et al. 2008).

In the case of locality 12, a soil profile consisting of 9 layers was identified on top of a weathered bedrock layer. The weathered layer correlates with the bedrock that forms the base of the soil profile of locality 1 (Figure 2). The layers of soil and sediment at locality 1 are mostly associated with paleosol development and fluvial activity. The layers are comprised of variable amounts of organicrich clay and sand; no gravel deposits were identified at locality 1 . Here, the organically enriched sediment layers were prime sample spots for obtaining paleoclimatic information using ${ }^{14} \mathrm{C}$ and the pollen profile. A primary objective is to improve our understanding of the paleoclimate records and geochronology of excavated archaeological sites in Korea. This can be achieved through multidisciplinary research efforts to unravel paleoclimate and environmental change of a specific Paleolithic site, and eventually, a regional correlation among sites. Our study is primarily focused on accelerator mass spectrometry (AMS) ${ }^{14} \mathrm{C}$ measurements for preliminary study of these 2 sites.

${ }^{14} \mathrm{C}$ dating soil horizons and associated organic materials requires special care. General soil dating methods are well established using organic materials, humic acid, and soil organic matter, etc. (Trumbore and Zheng 1996; Head and Zhou 2000; Kristiansen et al. 2003). Comparisons of soil ages using humic acid and humin fractions to determine an accurate ${ }^{14} \mathrm{C}$ dating method have been investigated by researchers at various geological sites. There is an ongoing debate concerning the accuracy of ${ }^{14} \mathrm{C}$ dating for the various materials (Martin and Johnson 1995; Pessenda et al. 2001; Xu and Zheng 2003; Tonneijck et al. 2006). The variability in ${ }^{14} \mathrm{C}$ ages of organic matter in soils underscores the care that should be taken during both sampling and chemical treatment procedures to

\footnotetext{
${ }^{1}$ Korea Institute of Geoscience and Mineral Resources, 30 Gajeong-dong, Yuseong-gu, Daejeon 305-350, Korea.

${ }^{2}$ Corresponding author. Email: kjkim@kigam.re.kr.

${ }^{3}$ NSF Arizona AMS Laboratory, University of Arizona, 1118 E. Fourth St., Tucson, Arizona 85721, USA.

${ }^{4}$ Institute of Korean Prehistory, 890 Bongmyeong-dong Heungdeok-gu, Cheongje, Chungbuk, Korea.
} 

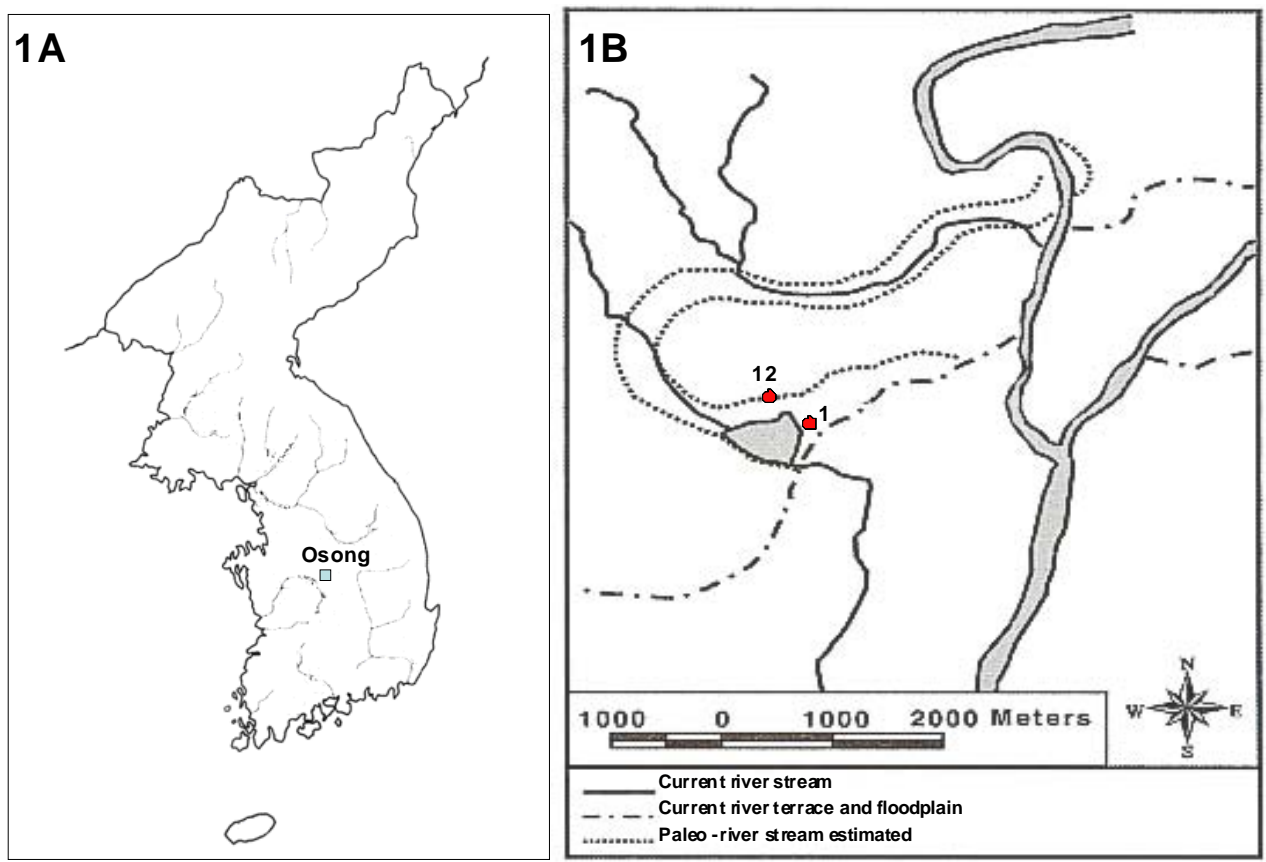

Figure 1 Sampling localities 1 and 12 of this investigation are shown on the current river and paleoriver stream map of the Mansuri region (modified after Kim 2007).

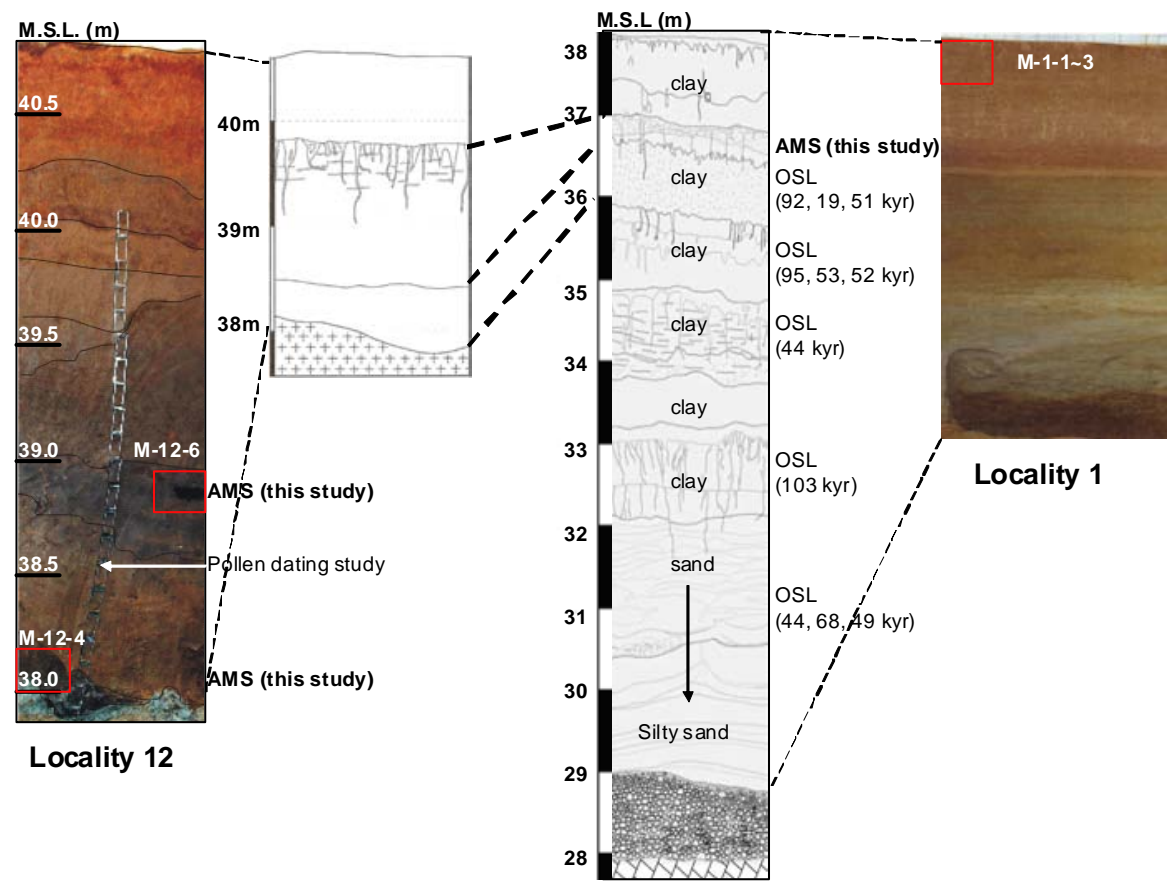

Figure 2 Soil profile information of localities 12 and 1, which include soil layers, sample spots (for AMS work in this investigation), OSL dates (Lee et al. 2008), and the pollen collecting device. 
remove soil contaminants. Obtaining both soil ages from humin and humic acid could help in more precise dating of Paleolithic surfaces and soil horizons. For soils with low carbon content, however, a low-temperature soil oxidization technique may be necessary (McGeehin et al. 2000).

\section{METHODS}

\section{Soil Dating of Locality 1}

In our preliminary investigation, we have measured ${ }^{14} \mathrm{C}$ dates for 1 layer of the upper part of the soil horizon at locality 1 and a total of 6 sample spots at locality 12. OSL dating results for at least 5 of the 13 layers of the soil horizon at locality 1 gave inconsistent results (see Figure 2; Lee 2007).

Samples were dated at either the new KIGAM AMS facility or at the University of Arizona. KIGAM's AMS facility uses an interconnected elemental analyzer and combustion system to produce $\mathrm{CO}_{2}$. Soil samples with low-level carbon content are not appropriate for this instrument. This is due to the limited sample size that the system can oxidize each time. Therefore, the samples from locality 1 were processed at the NSF Arizona Accelerator Mass Spectrometry (AMS) Laboratory at the University of Arizona to oxidize soil samples at $400{ }^{\circ} \mathrm{C}$. Some $200 \mathrm{mg}$ of soil samples were pretreated using an acid-alkali-acid (AAA) procedure (Jull et al. 2008). In sequence, the first acid treatment removes carbonates and fulvic acid, the base treatment eliminates humic acids, and the second acid treatment removes any remaining $\mathrm{NaOH}$. All of the treatments are accomplished overnight using a heating block at $70^{\circ} \mathrm{C}$. This pretreatment procedure of soils may require a much longer time when compared to the soil treatment method at KIGAM (detailed below; KIGAM AMS Lab 2008).

\section{Dating Organic Materials, Paleosols, and Bedrock from Locality 12}

At locality 12, organic-rich sediments were observed along the flattened wall (Figure 3) and an exposed ancient streambed located above the weathered bedrock. In the central part of Figure 3, dark areas are associated with carbon-rich materials, including a pile of large pieces of tree branches (i.e. $>10 \mathrm{~cm}$ ). Unlike at locality 1 , visible organic materials such as plant materials, parts of tree branches, seeds, roots, insects, and charcoals were easily identified. Figure 4 shows the organic materials obtained and dated from locality 12. Four large organic-rich soil samples, 4 pieces of wood, and a soil sample from the weathered bedrock (stratum) were collected from locality 12 (Figure 3). The stratum sample was embedded with many plant roots that were a few centimeters in length (Figure 4.6). These plant root pieces were collected (see Figure 4.7) and dated following AAA treatment. The 4 soil samples were $1-3 \mathrm{~kg}$ in size, so that the extractions of organic materials were feasible by sieving the soil material. Following the sieving step, various biological materials (e.g. seed, charcoal, and insects, etc.) were selected for dating using a microscope.

Soil dating was performed by extracting humic acid from 4 samples through the AAA pretreatment method from sampling spots 3, 4, 5, and 6 (Figure 3). At KIGAM, the pretreatment of soil to obtain humic acid is accomplished sequentially with an acid treatment of $0.5 \mathrm{M} \mathrm{HCl}$ for $30 \mathrm{~min}$, a base treatment of $0.5 \mathrm{M} \mathrm{NaOH}$ for $2 \mathrm{hr}$ at $80 \sim 85^{\circ} \mathrm{C}$, and a second acid treatment of $12 \mathrm{M} \mathrm{HCl}$. The age determinations for both the soil and organic materials are shown in Table 1.

\section{RESULTS}

\section{Locality 1}

The carbon contents of 3 samples (M-1-3), collected at locality 1 (see soil profile of Figure 2), are as low as $<0.24 \%$; it was not possible to obtain organic matter from the samples. Therefore, we per- 

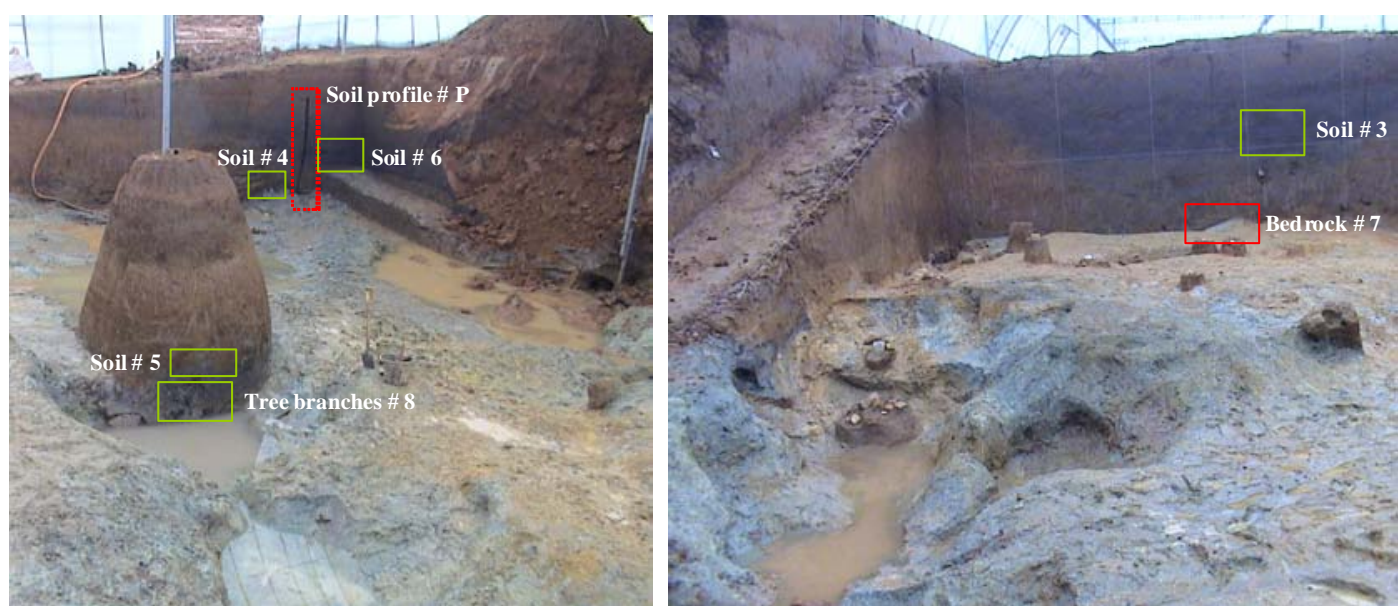

Figure 3 Photographs of the west side of locality 12 showing (left) the locations of sample spots 4, 5, 6, and 8 (highlighted in green) and soil profile \#P (highlighted in red) marking the location of the soil profile in Figure 2; and (right) sample spots 3 and 7 on the east side of locality 12.

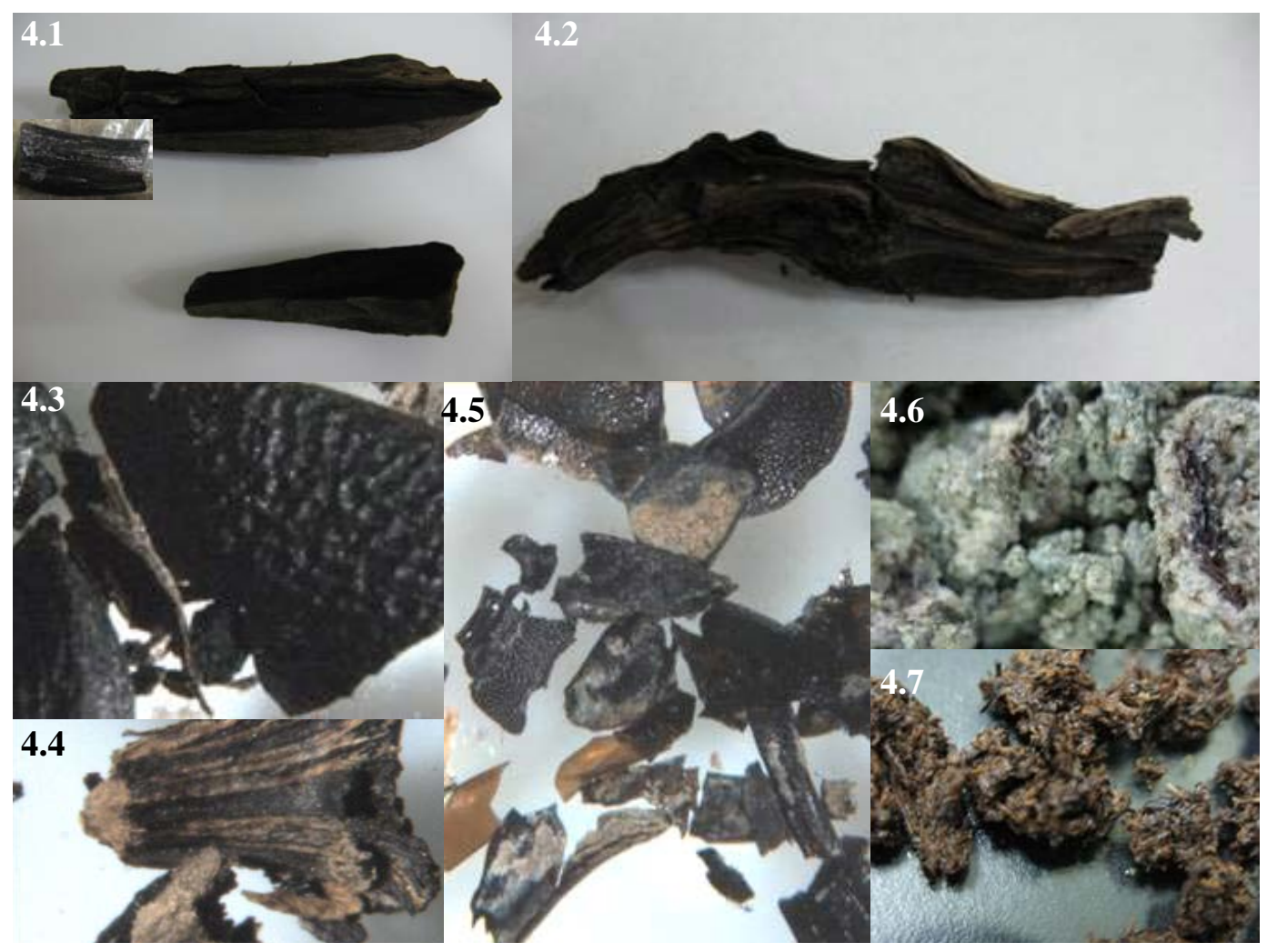

Figure 4 Photographs showing various organic materials obtained from locality 12. 4.1 and 4.2 show pieces of wood. The geometric shapes of the pieces of wood in 4.1 appear to indicate human-related modification compared to the naturally appearing wood (possible part of a root) of 4.2. In addition, 4.3 and 4.4 show pieces of seeds. 4.5 shows various pieces of insects. 4.6 shows weathered quartz-rich bedrock. 4.7 is a photo of thin $(\sim 2 \mathrm{~cm})$ roots extracted from the bedrock. 
formed a low-temperature oxidation technique at the Arizona laboratory (McGeehin et al. 2000). These samples were obtained from the top of the paleosol profile to study magnetic susceptibility of this region (Kim 2007).

Table 1 shows the ${ }^{14} \mathrm{C}$ ages of soil samples collected at depths of 1,13 , and $17 \mathrm{~cm}$ below the reference point of samples M-1-3 at locality 1, shown at the right side of Figure 2. The soil deposition rate at this locality ranges from 0.09 to $0.15 \mathrm{~mm} / \mathrm{yr}$ in the period from 33 to $31 \mathrm{kyr}$ BP. The soil age of locality 1 at $38 \mathrm{~m}$ asl of this study can be compared to the reported age range (19, 52, and $92 \mathrm{kyr}$ ) of soils at locality 1 determined using OSL (see Figure 2; Lee et al. 2008).

\section{Locality 12}

Biological materials and soils were collected from 6 spots at locality 12 to obtain chronological information using ${ }^{14} \mathrm{C}$ dating. The materials included plant seeds and insect fragments. Table 1 shows the ${ }^{14} \mathrm{C}$ ages of the various biological materials of locality 12 from elevations of $40.1 \mathrm{~m}$ asl down to $37.5 \mathrm{~m}$ asl. The carbon content in plant material and charcoal ranged from 44.8 to $54.4 \%$ and from 62.4 to $66.5 \%$, respectively (Table 1 ). The ages of charcoals were systematically older than those of plant materials, with a maximum age difference of about $3000 \mathrm{yr}$.

Table 1 Sample description and ${ }^{14} \mathrm{C}$ ages of localities 1 and 12. ${ }^{\mathrm{a}}$

\begin{tabular}{lllllll}
\hline Sample ID & Locality & $\begin{array}{l}\text { Sampling } \\
\mathrm{nr}\end{array}$ & $\begin{array}{l}\text { Elevation } \\
\text { (m asl) }\end{array}$ & $\begin{array}{l}\text { Sample description } \\
\text { (yr BP) }\end{array}$ & $\begin{array}{l}\text { Carbon } \\
(\%)\end{array}$ \\
\hline M-1-1.s & 1 & - & 38.4 & Low carbon paleosol & $31,000 \pm 1100$ & $<0.24$ \\
M-1-2.s & 1 & - & 38.27 & Low carbon paleosol & $31,900 \pm 1200$ & $<0.24$ \\
M-1-3.s & 1 & - & 38.23 & Low carbon paleosol & $32,800 \pm 1800$ & $<0.24$ \\
M-12-3.c & 12 & 3, East & 40.1 & Mostly charcoal & $1623 \pm 98$ & 66.5 \\
M-12-3.s & 12 & 3, East & 40.1 & Soil (humic acid) & $1660 \pm 40$ & - \\
M-12-4-ps & 12 & 4, West & 37.9 & Seed-buckwheat & $8787 \pm 109$ & 46.6 \\
M-12-4-p & 12 & 4, West & 37.9 & Plant & $7034 \pm 100$ & 44.8 \\
M-12-4-c & 12 & 4, West & 37.9 & Charcoal & $8742 \pm 101$ & 62.8 \\
M-12-4-s & 12 & 4, West & 37.9 & Soil (humic acid) & $9940 \pm 60$ & - \\
M-12-5.c & 12 & 5, Center & 38 & Charcoal & $9050 \pm 101$ & 62.4 \\
M-12-5.p & 12 & 5, Center & 38 & Plant & $5629 \pm 101$ & 54.4 \\
M-12-5.s & 12 & 5, Center & 38 & Soil (humic acid) & $9900 \pm 60$ & - \\
M-12-6.s & 12 & 6, West & 38.8 & Soil (humic acid) & $1580 \pm 40$ & - \\
M-12-7.b & 12 & 7, East & 38 & Roots on bedrock & $6048 \pm 100$ & 49.6 \\
M-12-8.w1 & 12 & 8, Center & 37.5 & Natural wood & $8588 \pm 101$ & 54.3 \\
M-12-8.w2 & 12 & 8, Center & 37.5 & Wood - artifact? & $7782 \pm 101$ & 53.9 \\
\hline
\end{tabular}

${ }^{a}$ Samples for locality 1 were measured at the NSF Arizona AMS Laboratory; the locality 12 samples were measured at the KIGAM AMS facility.

Figures 4.1 and 4.2 show wood samples found at locality 12 . When compared to the other 3 wood fragments in 4.1, this fragment appears unworked, compared to others that appear to be modified by humans into artifacts. The wood in 4.2 is a piece of the upper part of a root, whereas the geometric shapes of the others indicate modification (Figure 4). Detailed photos of seeds, insects, and bedrock samples are shown in Figures 4.3-4.7. In the upper-right corner of Figure 4.3, a triangular-shaped seed is similar to modern buckwheat. A whole seed and a few broken pieces of this type of seed were collected from sample spot 4 . 
Both the artifact wood and natural wood of spot 8 (Figures 4.1-4.2), respectively, which are located near the margin of the contact that separates the bedrock from the streambed, were determined to be older than both the plant root and leaf materials of the nearby ( $20 \mathrm{~m}$ ) sample spot 7. Sample spot 7 is located at a similar stratigraphic position/elevation to spot 8 (margin of the contact that separates the bedrock from the streambed). The ${ }^{14} \mathrm{C}$ age of plant roots, which were growing within the weathered bedrock, was determined to be $6048 \mathrm{yr}$ BP. The ${ }^{14} \mathrm{C}$ ages for these organic materials ranged from $5629 \pm 101$ to $9050 \pm 101$ yr BP (Table 1).

About $3 \mathrm{~m}$ higher in the stratigraphic profile (with respect to spots 7 and 8), sample spot 6 yielded a younger soil age of $1580 \pm 40 \mathrm{yr}$ BP. This age inversion also occurred in sample spots 3 and 6 of the east and west walls, respectively. These are located at the same stratigraphic positions of the water marks at the east and west walls (see Figure 3). Both show water marks and yield a similar age (1600 yr BP in Table 1). Thus, the 2 locations appear to indicate a paleo-streambed (Lee 2007). In addition, the identical ${ }^{14} \mathrm{C}$ ages of these 2 sampling spots support this conclusion.

Soil ages of spots 4 and 5 at the base of the streambed (Figure 3) using humic acid extraction were determined to be the same age, $9940 \pm 60$ and $9900 \pm 60$ yr BP, respectively. From the dates for spots 4 and 6 along the west wall of the excavation, which are located at different elevations (37.9 and $38.8 \mathrm{~m}$ asl, respectively), the soil deposition rate was determined to be $0.11 \mathrm{~mm} / \mathrm{yr}$. This rate is within the range of the soil deposition rate at locality 1 . However, the soil deposition rate above $37.9 \mathrm{~m}$ asl of locality 12 could be much higher than this value (see Figure 2).

\section{DISCUSSION}

Given the ${ }^{14} \mathrm{C}$ age of the 7 sampling sites at locality 12 (Figure 3), it can be concluded that this site is much younger than that of locality 1 . At locality 12, humic acid-based ages were determined to be similar to the charcoal ages in each spot (Table 1). At the bottom of the stratigraphic sequence, the contact separating the bedrock from the streambed (sample spots 4 and 5) records an age of $10 \mathrm{kyr}$ $\mathrm{BP}$, and soils are as young as $\sim 1.6 \mathrm{kyr} \mathrm{BP}$.

An archaeological report (Lee 2007) indicated that locality 12 has 4 soil horizons. Lee (2007) describes that the first horizon was recognized to be modified by historical human activity and fluvial activity. For example, pottery and stone artifacts were found from the historical period (Lee 2007), and water marks are visible throughout the profile. In conjunction with the dating work of this investigation, samples from the soil profile shown in Figure 2 of the west wall of locality 12 were collected for pollen studies (Yi 2009). The spiked appearance of specific pollen species (e.g. Quercus and Graimeae) at 2 stratigraphic positions ( $\sim 38$ and $\sim 40 \mathrm{~m}$ asl, respectively) indicate ages of 6 and 2 kyr BP (Figure 2), which are consistent with the age range determined in this investigation using ${ }^{14} \mathrm{C}$ soil dating.

The detailed stratigraphic information, identification of features such as watermarks, and the newly dated parts of the profile (e.g. contact separating bedrock from streambed) using the ${ }^{14} \mathrm{C}$ methodology at locality 12 of this investigation are consistent with the paleohydrological conditions shown in the current and river stream map of Figure 1. In addition, the ${ }^{14} \mathrm{C}$ ages of the organic materials, as well as identification of natural (root materials) and human-modified wood, as indicated by the geometric shapes, corroborate evidence compiled by other investigators (Lee et al. 2008) showing the influence of prehistoric Korean cultural activity in this region in the last 10 kyr BP. 


\section{CONCLUSION}

Our study reports soil ages from localities 1 and 12 of the Osong site to be between 10 and $31{ }^{14} \mathrm{C}$ kyr BP. Future work is needed to help constrain the chronological ages of environmental change at these Paleolithic sites, and we will date the paleosurfaces recently exposed through excavation using the cosmogenic nuclides ${ }^{10} \mathrm{Be}$ and ${ }^{26} \mathrm{Al}$.

\section{ACKNOWLEDGMENTS}

This work was supported by the Basic Project (10-3611) at the Korea Institute of Geoscience and Mineral Resources, and is partly supported for the work done at Arizona by NSF grant EAR0622305.

\section{REFERENCES}

Head MJ, Zhou WJ. 2000. Evaluation of $\mathrm{NaOH}$ leaching techniques to extract humic acids from palaeosols. Nuclear Instruments and Methods in Physics Research B 172(1-4):434-9.

Jull AJT, Burr GS, Beck JW, Hodgins GWL, Bidulph DL, McHargue LR, Lange TE. 2008. Accelerator mass spectrometry of long-lived light radionuclides. In: Povinec P, editor. Analysis of Environmental Radionuclides. Radioactivities in the Environment, Volume 11. Amsterdam: Elsevier. p 241-62.

KIGAM AMS Lab. 2008. Laboratory manual of chemical pretreatment for radiocarbon dating at the KIGAM AMS Laboratory. Daejon, Korea.

Kim JY. 2007. The Quaternary Geology of Mansuri Paleolithic Site, Cheongwon. In: The 1st Prehistoric Culture Seminar: Mansuri Paleolithic Site. Seoul: Institute of Korean Prehistory. p 59-77.

Kristiansen SM, Dalsgaard K, Holst MK, Aaby B, Heinemeier J. 2003. Dating of prehistoric burial mounds by ${ }^{14} \mathrm{C}$ analysis of soil organic matter fractions. Radiocarbon 45(1):101-12.

Lee YJ. 2007. Excavation and the significance of Mansuri Paleolithic Site, Cheongwon. In: The 1st Prehistoric Culture Seminar: Mansuri Paleolithic Site. Seoul: Institute of Korean Prehistory. p 13-43.

Lee YJ, Seo DW, Cheon GH. 2008. Investigation of the Mansu-ri Paleolithic site, Cheongwon, Korea. In: Derevianko AP, Shunkov MV, editors. The Current Issues of Paleolithic Studies in Asia. Novosibirsk: Publishing
Department of the Institute of Archaeology and Ethnography, Siberian Branch of the Russian Academy of Sciences. p 91-6.

Martin CW, Johnson WC. 1995. Variation in radiocarbon ages of soil organic matter fractions from Late Quaternary buried soils. Quaternary Research 43(2):232-7.

McGeehin J, Burr GS, Jull AJT, Reines D, Goss J, Davis PT, Muhs D. 2000. Comparison of sediment dating techniques. Radiocarbon 43(2B):687-90.

Pessenda LCR, Gouveia SEM, Aravena R. 2001. Radiocarbon dating of total soil or organic matter and humin fraction and its comparison with ${ }^{14} \mathrm{C}$ ages of fossil charcoal. Radiocarbon 43(2B):595-601.

Tonneijck FH, van der Plicht J, Jansen B, Verstraten JM 2006. Radiocarbon dating of soil organic matter fractions in Andosols in northern Ecuador. Radiocarbon 48(3):337-53.

Trumbore SE, Zheng S. 1996. Comparison of fraction methods for soil organic matter ${ }^{14} \mathrm{C}$ analysis. Radiocarbon 38(2):219-29.

Xu S, Zheng G. 2003. Variations in radiocarbon ages of various organic fractions in core sediments from Erhai Lake, SW China. Journal of Geochemistry 37(1):13544.

Yi SH. 2009. Archaeopalynological aspect of prehistoric maize pollen from late Holocene of western central Korea: a preliminary study. Journal of the Geological Society of Korea 45(6):697-709. 